\title{
Quantification of disease activity in Crohn's disease by computer analysis of Tc-99m hexamethyl propylene amine oxime (HMPAO) labelled leucocyte images
}

\author{
M H Giaffer, W B Tindale, S Senior, D C Barber, C D Holdsworth
}

\begin{abstract}
The reliability and clinical applications of computerised image analysis measurement of bowel uptake of Tc-99m HMPAO labelled leucocytes has been examined as a measure of disease activity in Crohn's disease. In 54 studies carried out on 33 patients with established Crohn's disease, the mean 'scan score', a quantitative assessment of image intensity, was $82 \cdot 1 \mathrm{SEM}(13 \cdot 6)$, in patients with clinically active disease compared to $24 \cdot 7(7 \cdot 0)$ in those with quiescent disease, $p \leq 0.0005$. A significant correlation was found between the scan score and Crohn's Disease Activity Index (rs= $0.52, \mathrm{p}<0.0001$ ), and Harvey and Bradshaw Simple Index $(r s=0.4, p<0.004)$. A low scan score correctly identified seven patients whose raised Crohn's Disease Activity Index incorrectly indicated active disease because symptoms used in calculation of the index were not caused by active inflammation. Of the laboratory measurements, the scan score correlated with the haemoglobin ( $r s=0.66, p<0.0001$ ), albumin level $(r s=-0.6, \quad p<0.0001)$, Creactive protein ( $r s=0.7, p<0.0001$ ), alphaacid glycoprotein ( $r s=0.57, p<0.001$ ), and platelet count ( $r s=0.47, p \leq 0.006$ ), but not with the erythrocyte sedimentation rate ( $r s=0 \cdot 2, p \leq 0 \cdot 25$ ). The scan score was raised in all patients who had clinically active disease but normal laboratory tests. The results of this study indicate that the scan score provides an objective indicator of disease activity in Crohn's disease which may be superior to clinical indices, and also to laboratory tests which although objective are often normal in the presence of active disease.
\end{abstract}

(Gut 1993; 34: 68-74)

There continues to be no generally accepted indicator of disease activity in Crohn's disease. Clinical indices ${ }^{1-3}$ depend heavily upon subjective features such as abdominal pain and well being. Laboratory measurements, ${ }^{+9}$ although more objective, are no more specific for Crohn's disease than the clinical indices. Endoscopic and radiological methods of assessment are invasive, need bowel preparation and are not suitable for all patients, particularly when repeated examina-

Bowel scintigraphy using Indium-111 labelled leucocytes has been applied to the assessment of disease extent and activity in Crohn's disease. Early results showed that bowel scans correlate with radiological, endoscopic, and histological methods of assessment. ${ }^{11}$ Measurement of faecal excretion of Indium-111 labelled leuco- cytes has been used to assess disease activity and has been shown to effectively distinguish active from quiescent Crohn's disease and to correlate with other clinical and laboratory activity indices. ${ }^{12}$ This, however, needs patient cooperation, depends upon bowel frequency and for optimum results requires granulocyte purification which is time consuming.

Tc-99m hexamethyl propylene amine oxime (HMPAO) has recently been introduced for regional cerebral blood flow imaging, ${ }^{13}$ but has subsequently been found to selectively label granulocytes in mixed leucocyte suspensions. ${ }^{1+}$ Although hitherto largely used to localise infection and inflammation, ${ }^{14}$ preliminary experience with this tracer as a leucocyte label in inflammatory bowel disease has been encouraging. ${ }^{14} 15$

As a result of the short half-life of Tc- $99 \mathrm{~m}$ and its biliary excretion, meaningful faecal excretion studies using this isotope are not possible. Disease activity must therefore be derived from the degree of abnormal bowel uptake on abdominal scans. The only method previously applied to quantify the abnormal bowel uptake on abdominal scans obtained using either Indium-111 or Tc-99m HMPAO labelled leucocytes has been the visual comparison of the intensity of bowel uptake with that of liver, spleen and bone marrow. ${ }^{11} 1617$ This method is very crude and subjective. We have therefore developed a computer based technique for the quantification of bowel uptake and have applied it to images of the distribution of Tc-99m HMPAO labelled leucocytes. The bowel uptake as a measure of Crohn's activity was then correlated with other established clinical and laboratory indicators of disease activity.

\section{Methods}

\section{PATIENTS}

Fifty four studies were performed on 33 patients with Crohn's disease, the diagnosis having been established by standard clinical, radiological, and/or histological criteria. There were 23 women and 10 men (mean age 43 years, range 19-75). In six cases the diagnosis was confirmed shortly before the scan; the remaining 27 had long standing disease (mean duration 8.4 years, range 1-32). The disease had recurred at a previous ileocolonic anastomosis in seven patients and predominantly affected the small bowel, the large bowel and both small and large intestine in nine, nine, and eight patients respectively. tions are required.

Gastroenterology Unit,
M H Giaffer
C D Holdsworth
Department of Medical
Physics, Royal
Hallamshire Hospital,
Sheffield
W B Tindale
S Senior
D C Barber
Correspondence to:
Dr C D Holdsworth,
Gastroenterology Unit, Royal
Hallamshire Hospital, Glossop
Road, Sheffield S10 2JF.
Accepted for publication
8 June 1992




\section{DISEASE ACTIVITY}

Disease activity was assessed using: (A) Crohn's Disease Activity Index - CDAI,' the disease being considered active if the CDAI value was greater than 150. (B) Simple Index of Harvey and Bradshaw - SI. ${ }^{2}$. A value of $\geq 4$ denotes active disease. (C) Laboratory tests reflecting active gut inflammation, ${ }^{+9}$ these included: haemoglobin: normal: male $\geq 12.5 \mathrm{~g} / \mathrm{dl}$, female $\geq 11 \cdot 5 \mathrm{~g} / \mathrm{dl}$; platelet count: normal: $150-400 \times$ $10^{9} / 1$; erythrocyte sedimentation rate: normal: $\leq 20 \mathrm{~mm}$ in first hour; serum albumin: normal: $\geq 35 \mathrm{~g} / \mathrm{l}$; C-reactive protein: normal: $\leq 4 \mathrm{mg} / \mathrm{l}$; alpha-1 acid glycoprotein: normal: $\leq 1 \cdot 2 \mathrm{~g} / \mathrm{l}$.

The clinical indices and laboratory measurements were made within one week of having the bowel scan. The CDAI and Simple Index calculations were available for analysis on 51 and 50 studies (33 patients) respectively. The results of haemoglobin, platelet count, C-reactive protein, alpha- 1 acid glycoprotein, serum albumin, and erythrocyte sedimentation rate were available from $32,32,30,30,30$, and 28 patients respectively. All available studies were used in examining the correlations between the scan score and the CDAI and Simple Index. Because some patients had repeated studies to monitor the effects of treatment, however, and as such treatment may affect the scan score without necessarily affecting the laboratory tests, only the initial scans obtained before administering any therapy were used in correlations between scan score and laboratory indicators of disease activity.

\section{LEUCOCYTE LABELLING}

The technique of labelling granulocytes in mixed leucocyte suspensions using Tc-99m HMPAO has previously been described. ${ }^{18}$ Briefly, $102 \mathrm{ml}$ venous blood were taken into $18 \mathrm{ml}$ of acidcitrate-dextrose. Twenty millilitres were centrifuged at $1500 \mathrm{~g}$ for 10 minutes to obtain cell free plasma. To the remaining $100 \mathrm{ml}$ of blood $10 \mathrm{ml}$ of $6 \%$ hydroxyethyl starch (Hespan, Dupont, USA) was added and left to sediment at room temperature. The supernatant containing platelets and white blood cells was centrifuged to separate the leucocytes which were then resuspended in cell free plasma. Tc-99m HMPAO was reconstituted according to the manufacturer's instructions.

Four millilitres of the complex were immediately added to the leucocyte suspension, gently mixed and left for 10 minutes at room temperature. The labelled cells were washed once with cell free plasma before being transferred to a syringe for reinjection. An average of $200 \mathrm{MBq}$ of $\mathrm{Tc}-99 \mathrm{~m}$ labelled cells were injected into each patient.

IMAGING AND CALCULATION OF THE SCAN SCORE A dynamic study of the posterior lung fields was carried out for the first 15 minutes after injecting the radiolabelled leucocytes. Subsequently anterior and posterior abdominal scans were obtained at 40,120 , and 240 minutes using a large field of view gamma camera fitted with a low energy high resolution collimator and inter- faced to a Research Machines Nimbus microcomputer. No scintigrams showed prolonged lung retention of labelled cells, which has been shown to indicate cell injury during labelling. ${ }^{19}$

The bowel activity was quantified by calculating a scan score from the images obtained at 120 minutes. The method involves the generation of a 'normal' or background image which contains only bone marrow, liver and spleen activity. Any patient image can be considered to be composed of this normal image, upon which abnormal gut uptake is superimposed. By subtracting a 'normal' image from the patient's abdominal scan, abnormal gut uptake may be isolated from the background distribution of labelled cells. The 'normal' image was generated from the first 12 scans obtained from patients with Crohn's disease. Details of the technique used are given in Tindale et al..$^{20}$ Briefly, the method involves scaling all the images to a standard body size and position and to a fixed magnitude. A weighted mean of all the scaled images is then calculated, with the weighting factor being selected in order to bias against the presence of any abnormalities. This procedure will tend to remove features which are only present on individual images, while retaining those features which are common to all images. The resulting weighted mean image is shown in Figure $1 \mathrm{~A}$ and was taken to represent the average background activity in the population studied.

To determine the scan score for an individual patient, the patient's image is first scaled in size to fit the normal image (Fig 1B), and the normal image is then subtracted from that of the patient. This gives good separation of the abnormal bowel from the background activity (Fig 1C). The scan score is then calculated from the counts in a $20 \%$ contour based on the maximum pixel value in the abnormal gut. This value is normalised to correct for variation in injected dose and image acquisition times. All images were evaluated by one of the authors (WBT) without previous knowledge of the results of the clinical or laboratory tests, which were collected separately without knowledge of the scan score. In addition, disease activity was assessed on the two hour films by visually comparing the bowel uptake of Tc-99m HMPAO with that of bone marrow, liver, and spleen. The bowel area was divided into five segments and a score given to each segment depending whether the bowel uptake was $\leq$ bone marrow (grade 1), > bone marrow but $\leq$ liver (grade 2), >liver but $\leq$ spleen (grade 3 ) or $>$ spleen (grade 4). If no uptake was seen a grade of $(0)$ was given as described elsewhere."

\section{STATISTICAL ANALYSIS}

The scan score is a dimensionless quantity, the magnitude of which is related to the degree of abnormal uptake in the gut. All values for patient groups are presented as mean (SEM). The Mann-Whitney test was applied to examine the difference between the scan score in active and quiescent disease. Correlations between the scan score and the CDAI, Simple Index, and the laboratory measurements were tested by Spearman's equation, where rs denotes Spear- 


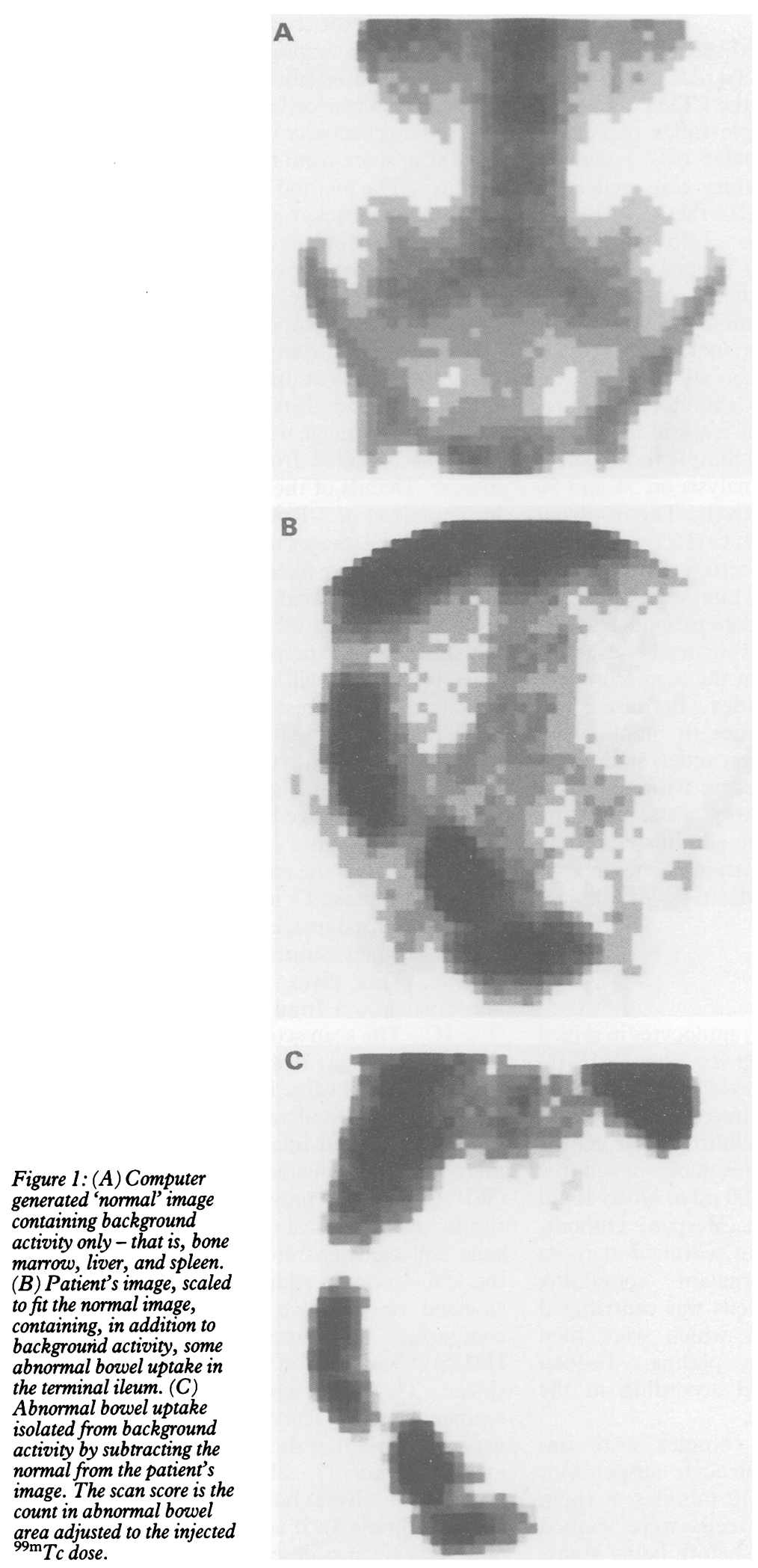

man's coefficient and $\mathrm{p}$, the associated probability.

\section{Results}

The viability of the injected leucocytes was estimated at $95 \%$ using the standard trypan blue exclusion test. After injection of the labelled leucocytes, radioactivity on the abdominal scan was distributed so that spleen $>$ liver $>$ bone marrow; in some cases, urinary bladder activity also appeared.

Bowel uptake was evident as early as 40 minutes. Some hepatobiliary excretion -was evident on some of the four hour images, as noted by previous workers. ${ }^{21}$ Compared with Indium-111, the image quality of $\mathrm{Tc}-99 \mathrm{~m}$ HMPAO scans was superior.

Reproducibility studies on the data used to calculate the scan score yielded a coefficient of variation of $5 \cdot 5 \%$.

\section{DISEASE ACTIVITY}

Figure 2 shows that patients with active Crohn's disease have a significantly higher scan score (mean 82.1 (13.6), median 51) than those with quiescent disease (mean $24 \cdot 7(7 \cdot 0)$, median 15) $(p \leq 0.005)$. Optimum separation between the groups was attained with a threshold scan score of 20 . On this basis, the technique had a sensitivity of $82 \%$, a specificity of $77 \%$, a predictive value of $91 \%$, and a false positive rate of $8 \cdot 8 \%$. Discordance between the CDAI and the scan score was observed on 10 occasions. In seven of these, raised CDAI >150 was associated with relatively low scan score $(\leq 20)$. In each of these patients it was clear that the raised CDAI was caused either by the presence of symptoms which although contributing substantially to the

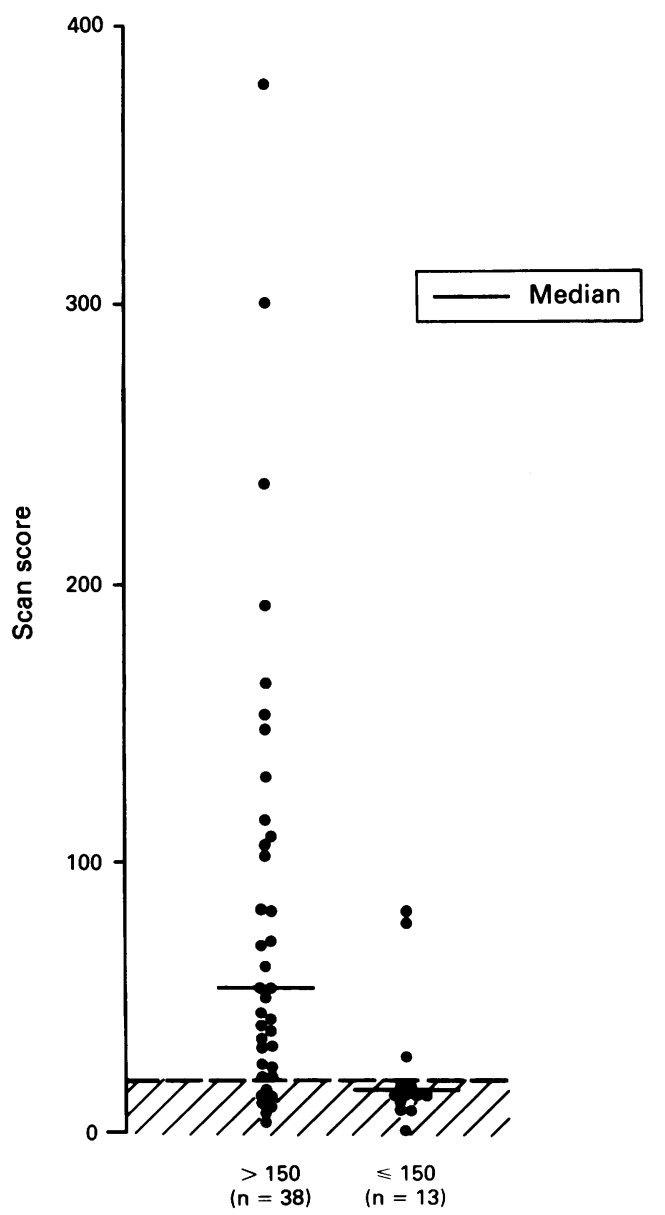

Crohn's disease activity index

Figure 2: Scan score in patients with active and quiescent Crohn's disease. A threshold of 20 (shaded area) separates the two groups with the highest predictive value and overall accuracy. 


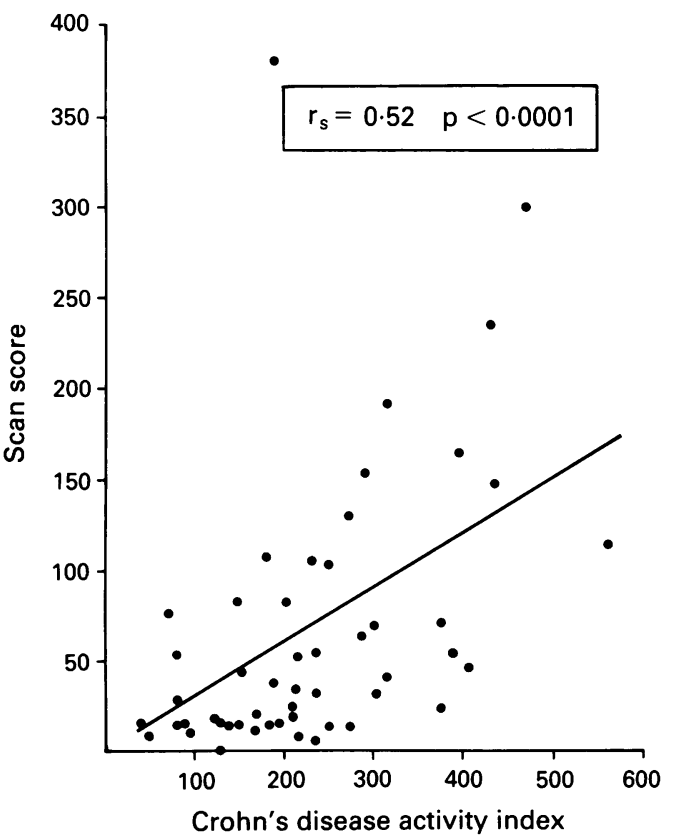

Figure 3: Correlation between scan score and Crohn's Disease Activity Index.

CDAI were not caused by active inflammation for example, superimposed symptoms of irritable bowel syndrome in three patients and subacute intestinal obstruction from fibrous stricture in two patients, or to symptomatic anaemia (one case). One patient with Crohn's colitis had CDAI of 376 (main symptoms were diarrhoea and feeling unwell) and scan score of $13 \cdot 1$ but only 'mild' inflammatory changes were demonstrated endoscopically and histologically.

On the other hand, a normal CDAI of less than 150 but a high scan score indicating active Crohn's disease was recorded in three scans. Two of these were from one patient with newly diagnosed and radiologically active terminal ileal Crohn's disease who was treated with elemental diet for four weeks. An initial scan score of 77.9 decreased to 29.9 after dietary treatment. The third scan came from a patient with Crohn's colitis who despite the absence of symptoms continued to have persistently abnormal laboratory tests and a scan score of $80 \cdot 6$. Clearly in these three patients the abnormal scan score was

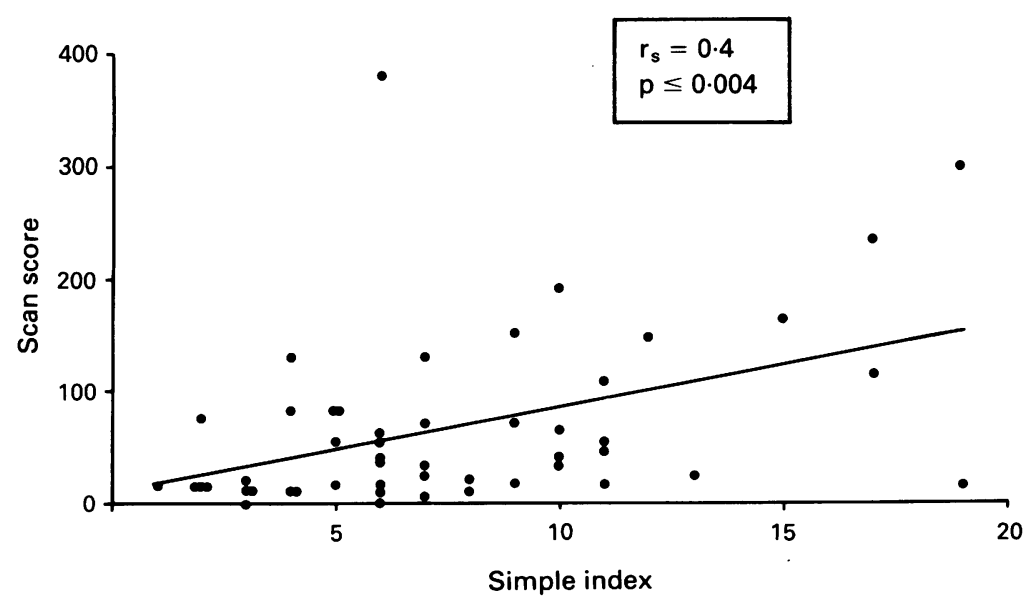

Figure 4: Correlation between scan score and Simple Index of Harvey and Bradshaw. a more accurate indicator of the degree of activity than the CDAI.

When disease activity was assessed using the visual grading method by two independent observers, there was complete agreement in only $26 \%$ of scans. A difference of at least two grades was recorded in $30 \%$ of cases. The visual grading score was high indicating active disease in nine $(45 \%)$ of the 20 scans taken from patients with clinically quiescent disease and who had a low ( $\leq 20)$ scan score.

As shown in Figures 3 and 4, the scan score correlated significantly with the CDAI and the Simple Index. The scan scores were not statistically different in patients with predominantly small bowel disease (mean CDAI 209 (28), mean scan score $73 \cdot 3(16 \cdot 2)$ ), large bowel involvement (mean CDAI 275 (44), mean scan score 94.4 (33)), and disease affecting both small and large intestine (mean CDAI 344 (61), mean scan score $94 \cdot 1(19 \cdot 2))$.

Data in the Table show that the scan score correlated significantly with all laboratory measurements except the erythrocyte sedimentation rate. Correlations with the $\mathrm{C}$-reactive protein and serum alpha-1 acid glycoprotein which some authors have claimed to be the most reliable laboratory indicators of activity ${ }^{3-5}$ are further illustrated in Figures 5 and 6 . It can be seen that no patient with a serum C-reactive protein above $4 \mathrm{mg} / \mathrm{dl}$ or alpha-1 acid glycoprotein above $1 \cdot 2 \mathrm{~g} / \mathrm{l}$ had a scan score below 20 .

Twelve patients with clinically active disease had normal erythrocyte sedimentation rate values; all of these had raised scan score. Similarly the scan score was raised in all patients with clinically active disease $(\mathrm{CDAI} \geq 150)$ but normal haemoglobin (7), platelet count (7), or alpha-1 acid glycoprotein (7). Correlation between the scan score and laboratory tests varied with disease location. In patients with Crohn's colitis, the scan score correlated with all tests except for erythrocyte sedimentation rate and alpha-1 acid glycoprotein (Table). On the other hand, when the disease was confined to the small bowel, significant correlations were found only with the serum albumin, alpha-1 acid glycoprotein, and haemoglobin. Correlation with platelet count was particularly good in colonic disease.

\section{Discussion}

The ideal test for the assessment of disease activity in Crohn's disease should be simple, objective, reliable, and amenable to serial measurements to allow the assessment of various therapeutic interventions, particularly in severely ill patients who usually tolerate other invasive diagnostic tests badly. Unfortunately, none of the available tests meet these goals. The various clinical activity indices in general use ${ }^{1-3}$ depend on subjective features for their calculation and are of little use in day to day patient management, but do at least provide a tool which enables comparison of data obtained from different centres. They have hitherto been the most generally used in clinical trials. The laboratory tests lack specificity and can be normal in the presence of clinically active disease. ${ }^{22}$ The use 


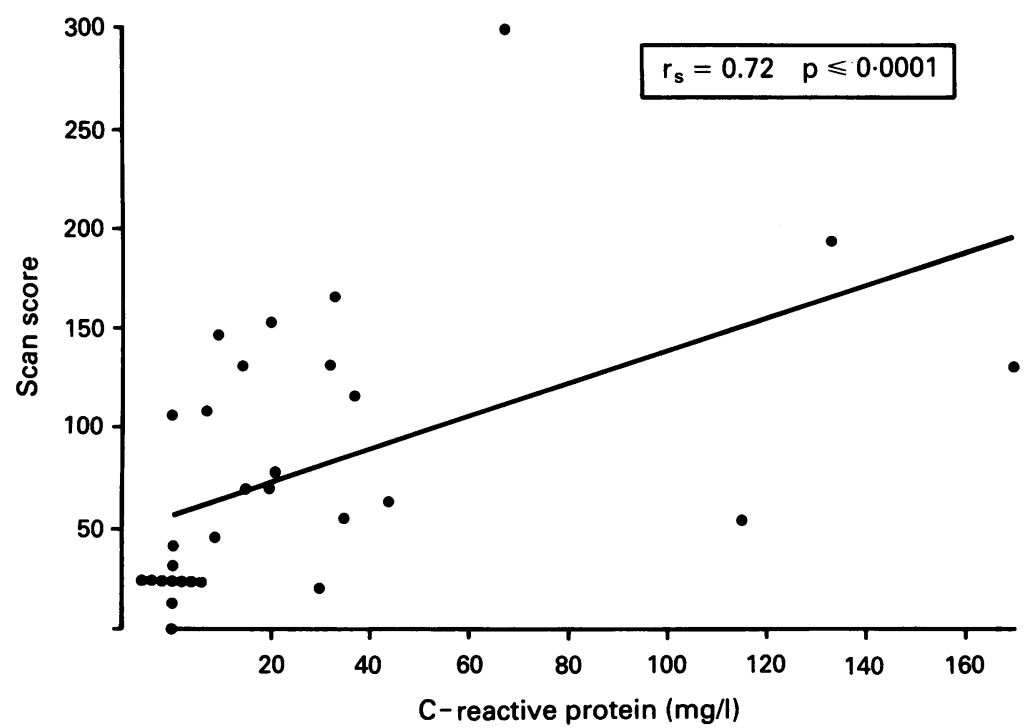

Figure 5: Correlation between scan score and C-reactive protein.

of radiolabelled leucocytes to localise and estimate disease activity in inflammatory bowel disease provides an objective technique for the assessment of disease activity. Of the radioisotopes which have been used for labelling leucocytes, Indium-111 is the most widely studied. ${ }^{10-12}{ }^{17}$ Its long half life (67 hours) permits faecal excretion studies, which are considered by some as the 'gold standard' parameter of disease activity in Crohn's disease. ${ }^{12}$ The need for collection of stools over four days, and a radiation dose limiting repeated studies are the main disadvantages of faecal indium excretion studies.

Tc-99m HMPAO, unlike other Tc-99m agents, is relatively stable in granulocytes compared with other blood cells and can therefore be used as a selective granulocyte label without the need for the tedious technique required for the separation of these cells from mixed leucocyte suspensions. From the point of view of radiation dosimetry, image quality, availability and relative expense Tc- $99 \mathrm{~m}$ is preferable to Indium111. The presence of non-specific biliary excretion and short half life, however, render faecal collection studies after Tc-HMPAO labelled leucocytes of little clinical use. Disease activity must be estimated from the bowel scintigrams instead. The only method hitherto available for the quantification of bowel activity on abdominal scans has been the grading of the bowel uptake by visually comparing it with that of the spleen, liver, and bone marrow. "16 17 This method is as subjective as the clinical indices and depends upon the presence of normal spleen, liver, and

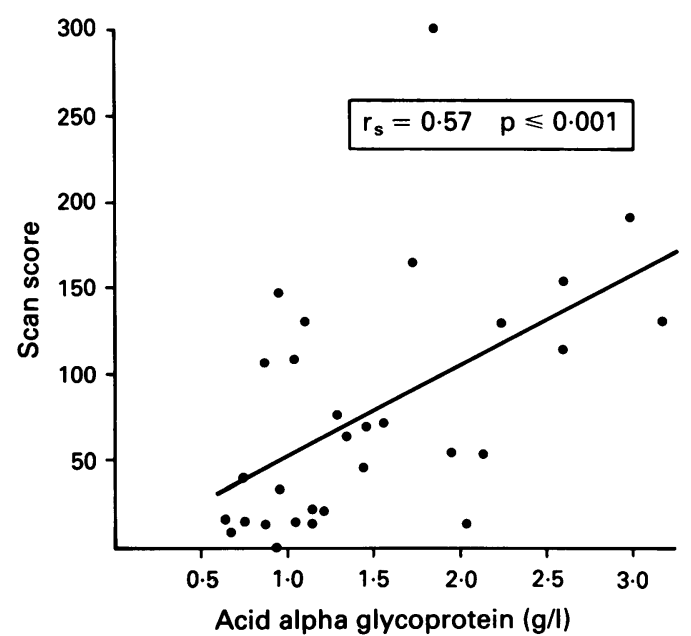

Figure 6: Correlation between scan score and alpha acid glycoprotein.

bone marrow. Variations in the uptake of labelled leucocytes in these organs have been reported $^{21}$ and patients with inflammatory bowel disease may have associated hyposplenism ${ }^{23}$ which may affect the splenic uptake. In calculating the scan score, it is essential to separate the abnormal bowel uptake from the background activity. Without such separation disease activity will frequently be overestimated particularly when the disease is quiescent (data not shown). Although not the objective of this study, we have compared our method with that in which disease activity was estimated by comparing the bowel uptake with that of the bone marrow, spleen, and liver.

We found poor correlation between the two methods with the visual grading method having a significant interobserver variation. A significant proportion of our patients who had clinically quiescent disease and who had a low scan score were classed as having active disease by the visual grading method. In patients with active disease, the visual score tended to under estimate disease activity.

The computer based analysis of bowel images described in this paper meets most of the criteria for an ideal activity marker activity in Crohn's disease. The scan score is objective, and reliably differentiates between active and inactive Crohn's disease. The seven patients with spuriously raised CDAI as a result of noninflammatory conditions or complications of Crohn's disease, such as fibrous strictures, were correctly identified by the scan score. We found the scan score particularly helpful in the accurate estimation of disease activity in these circum-

TABLE Correlation matrix between scan score and laboratory tests in patients with Crohn's disease

\begin{tabular}{|c|c|c|c|c|c|c|}
\hline & \multicolumn{2}{|c|}{ Small bowel disease } & \multicolumn{2}{|c|}{ Large bowel disease } & \multicolumn{2}{|l|}{ All sites } \\
\hline & $r s$ & $p$ & $r s$ & $p$ & $r s$ & $p$ \\
\hline $\begin{array}{l}\text { Haemoglobin } \\
\text { Erythrocyte sedimentation rate } \\
\text { Platelet count } \\
\text { Serum albumin } \\
\text { C-reactive protein } \\
\text { Alpha-acid glycoprotein }\end{array}$ & $\begin{array}{c}-0.58 \\
0.2 \\
0.53 \\
-0.8 \\
0.46 \\
0.8\end{array}$ & $\begin{array}{l}0.01 \\
\text { NS } \\
0 \cdot 05 \\
0.0057 \\
\text { NS } \\
0.0059\end{array}$ & $\begin{array}{c}-0.879 \\
0.4 \\
0.92 \\
-0.81 \\
0.711 \\
0.56\end{array}$ & $\begin{array}{l}0 \cdot 001 \\
\text { NS } \\
0 \cdot 0006 \\
0 \cdot 008 \\
0.03 \\
0.09\end{array}$ & $\begin{array}{r}-0.66 \\
0.22 \\
0.47 \\
-0.61 \\
0.72 \\
0.57\end{array}$ & $\begin{array}{l}0.0001 \\
\mathrm{NS} \\
0 \cdot 006 \\
0 \cdot 0001 \\
0 \cdot 0001 \\
0 \cdot 001\end{array}$ \\
\hline
\end{tabular}

rs $=$ Spearman's correlation coefficient

$\mathrm{p}_{\mathrm{NS}}=$ Associated probability

NS $=$ Not significant 
stances, often enabling unnecessary therapeutic manipulations to be avoided. Conversely our three patients with a normal CDAI value but raised scan score all had some other confirmatory evidence of active gut inflammation such as persistently abnormal laboratory tests or palpable abdominal mass. This shows that the clinical indices can underestimate disease activity, this being particularly likely when there are minimal abdominal symptoms or when presentation is with features such as weight loss.

The scan score correlated with all laboratory tests generally accepted to reflect active gut inflammation ${ }^{22}$ except for the erythrocyte sedimentation rate. Although the erythrocyte sedimentation rate has been used to measure disease activity in inflammatory bowel disease ${ }^{3+}$ and to predict relapse after treatment, ${ }^{2+}$ it is frequently normal in some patients with unequivocally active disease. ${ }^{2+25}$ Our data support the results of other studies which have found the erythrocyte sedimentation rate to be of very limited value. Powell-Tuck ${ }^{26}$ found no significant correlation between the erythrocyte sedimentation rate and sigmoidoscopic appearance in patients with ulcerative colitis and in Crohn's disease. Cooke and Prior $^{25}$ showed that serum C-reactive protein and albumin but not the erythrocyte sedimentation rate correlated with disease activity. The scan score correlated well with C-reactive protein and alpha-1 acid glycoprotein. Both are considered by some as the most reliable markers of disease activity in Crohn's disease. ${ }^{427}$ Although haemoglobin concentration and serum albumin may be affected by factors other than active gut inflammation such as malnutrition and bleeding, hypoalbuminaemia, and anaemia are frequent features of active Crohn's disease. ${ }^{2829}$ The scan score correlated with both albumin and haemoglobin. It is of interest that the correlation between the scan score and albumin is highest in patients with small bowel involvement.

One of the main applications of the scan score is in difficult cases when accurate estimation of disease activity will have important therapeutic implications. Laboratory tests are frequently normal in patients with unequivocally active disease and vice versa. ${ }^{22}$ Symptoms may therefore be erroneously attributed to other noninflammatory conditions. The scan score is particularly useful in these circumstances for its sensitivity approaches $100 \%$. Conversely, patients with quiescent disease who continue to have persistently abnormal blood tests have a high recurrence rate. ${ }^{30-32}$ The scan score showed that this is probably caused by the presence of subclinical active gut inflammation for all of these patients had raised scan score. A further important value of the scan score is in serial studies in individuals particularly in the context of therapeutic trials. We have recently shown that in patients with Crohn's disease treated with elemental diet remission can be defined more objectively by the use of the scan. ${ }^{33}$

In summary, the computer based analysis of bowel images obtained from patients with Crohn's disease meets most of the criteria for an ideal marker of disease activity. Tc- $99 \mathrm{~m}$ HMPAO is widely available, delivers a relatively small radiation dose, has a short half life and because of its emission characteristics produces pictures of superior quality to those obtained with Indium-111. The calculation of the scan score from these images provides a reliable and objective indicator of disease activity. This indicator can reliably differentiate between active and quiescent disease and is particularly useful in difficult cases when symptoms may not reflect active disease or when severe symptoms are not backed by abnormal laboratory tests. The scan score correlates well with widely used clinical and laboratory markers of disease activity. Of these, correlations with the serum albumin, and alpha-1 acid glycoprotein particularly in small bowel disease, and C-reactive protein, particularly in large bowel disease, were the most significant. The complete lack of correlation with the erythrocyte sedimentation rate reinforces the finding of other studies showing that this laboratory test may not be as useful as once thought in the assessment of Crohn's disease activity, whereas the value of raised platelet count was confirmed, particularly in colonic disease. The method is particularly valuable as an objective measurement to assess the response to therapy.

This work was supported by a grant from Cow \& Gate/Nutricia and the Trustees of the Former United Sheffield Hospitals.

1 Best WR, Becktel JM, Singleton JW, Kern F. Development of a Crohn's disease activity index. National Co-operative Crohn's Disease Study Gastroenterology 1976; 70: 439-44.

2 Harvey RF, Bradshaw JM. A simple index of Crohn's disease activity. Lancet 1980; i: 514

3 Van Hees PAM, Van Elteren PM, Van Lier HJ, Van Tongeren HM. An index of inflammatory activity in patients with Crohn's disease. Gut 1980; 21: 279-86.

4 Andre C, Descos L, Landias P, Fermanian J. Assessment of appropriate laboratory measurements to supplement the Crohn's disease activity index. Gut 1981; 22: 571-4.

5 Fagan EA, Dyck RF, Maton PN, Hodgson HJ, Chadwick VS, Petrie A, et al. Serum levels of C-reactive protein in Crohn's disease and ulcerative colitis. Eur $\mathcal{F}$ Clin Invest 1982; 12: 351-9.

6 Harries AD, Fitzsimons E, Fifield R, Dew MJ, Rhodes J Platelet count: a simple measure of activity in Crohn's disease. $B M F$ 1983; 286 : 1476 .

7 Talstad I, Gjone E. The disease activity of ulcerative colitis and Crohn's disease. Scand F Gastroenterol 1976; 11: 403-8.

8 Dearing WH, McGuckin WF, Elueback LR. Serum Alpha-1acid glycoprotein in chronic ulcerative colitis. Gastroenterology 1969; 56: 295-303.

9 Cooke WT, Fowler DI, Cox EV, Gaddie R, Meynell MJ. The clinical significance of seromucoids in regional ileitis and ulcerative colitis. Gastroenterology 1958; 34: 910-9.

10 Saverymuttu SH, Peters AM, Hodgson HJ, Chadwick VS Lavender JP. Indium-111 autologus leucocyte scanning: comparison with radiogy for imasing the colon in inflam matory bowel disease. BMF 1982; 285: 255-7.

11 Saverymuttu SH, Camilleri M, Rees H, Lavender JP Saverymuttu SH, Camilleri M, Rees H, Lavender JP,
Hodgson HJF, Chadwick VS. Indium-111 granulocyte Hodgson HJF, Chadwick activity in inflammatory bowel disease. Gastroenterology activity in inflam

12 Saverymuttu SH, Peters AM, Lavender JP, Pepys MB Hodgson HJF, Chadwick VS. Quantitative faecal Indium11 labelled leukocyte excretion in the assessment of disease in Crohn's disease. Gastroenterology 1983; 85: 1333-9.

13 Ell PJ, Jarritt PH, Cullum I, Hocknell JML, Costa DC, Lu $\mathrm{D}$, et al. Regional cerebral blood flow mapping with a new ${ }_{99} \mathrm{Tc}^{\mathrm{m}}$-labelled compound. Lancet $1985 ;$ ii: $50-1$.

14 Peters AM, Danpure HJ, Osman S, Hawker RJ, Henderson $\mathrm{BL}$, Hodgson HJ, et al. Clinical experience with ${ }^{99} \mathrm{Tc}^{\mathrm{m}}$ hexamethyl propylene amine oxime for labelling leucocytes and imaging inflammation. Lancet 1986; ii: $946-9$.

15 Schumichen C, Scholmerich EJ, Freiburg B. Tc-99m HMPAO labelling of leucocytes for detection of inflammaHMPAO labelling of leucocytes for detection of

16 Scholmerich J, Schmidt E, Schumichen C, Billmann P, Schmidt H, Gerok W. Scintigraphic assessment of bowel involvement and disease activity in Crohn's disease using involvement and disease activity in Crohn's disease using Technetium 99m-Hexamethyl propylene amine
leukocyte label. Gastroenterology 1988; 95: 1287-93.

17 Stein DT, Gray GM, Gregory PB, Anderson M, Goodwin DA, McDougall IR. Location and activity of ulcerative and
Mcin DT, Gray GM, Gregory PB, Anderson $M$, Goodwin DA, Crohn's colitis by Indium-111 leukocyte scan. Gastroenterologv 1983; 84: 388-93.

18 Danpure $\mathrm{HJ}$, Osman S, Carroll MJ. The development of 
clinical protocol for the radiolabelling of mixed leucocytes with ${ }^{99 m} \mathrm{Tc}$ Hexamethyl propylene amine oxime. Nucl Med Commun 1988; 9: 465-75.

19 Saverymuttu SH, Peters AM, Danpure HJ, Reavy HJ, Osman S, Lavender JP Lung transit of ${ }^{111}$ Indium labelled granulocytes. Relationship to labelling techniques. Scand $\mathcal{F}$ Haematol 1983; 80: 151-60.

20 Tindale WB, Barber DC, Giaffer MH, Senior S, Holdsworth CD. 99m-Tc HMPAO labelled leucocyte imaging in Crohn's disease: a subtraction technique for the quantification of disease: a subtraction technique for the quantification
disease activity. Clin Phys Physiol Meas 1992; 13: 37-50.

21 Peters AM, Roddie ME, Danpure HJ, Osman S, Zacharopoulos GP, George P, et al. ${ }^{99} \mathrm{Tc}^{\mathrm{m}}-\mathrm{HMPAO}$ labelled leucocytes: comparison with "III In-tropolonate labelled granulocytes. Nucl Med Commun 1988; 9: 449-63.

22 Bartholomeusz FDL, Shearman DJC. Measurement of activity in Crohn's disease. $\mathcal{F}$ Gastroenterol Hepatol 1989; 4 : 81-94.

23 Palmer KR, Sherriff SB, Holdsworth CD, Ryan FP. Further experience of hyposplenism in inflammatory bowel disease. Qf Med 1981; 200: 463-71.

24 Brignola C, Campieri M, Bazzocchi C, Farruggia P, Tragnone A I anfranchi $\mathrm{G}$. A laboratory index for predicting relapse in asymptomatic patients with Crohn's disease. Gastroenterology 1986; 91 : 1490-4.

25 Whittington PF, Verdain Barnes H, Bayless TM. Medical management of Crohn's disease in adolescence. Gastroenterology 1977; 72: 1338-44.
26 Cooke WT, Prior P. Determining disease activity in inflammatory bowel disease. $\mathcal{F}$ Clin Gastroenterol 1984; 6: 17-25.

27 Powell-Tuck J, Day DW, Buckell NA, Wadesworth J Lennard-Jones JE. Correlations between defined sigmoidoscopic appearances and other measures of disease activity in ulcerative colitis. Dig Dis Sci 1982; 27: 533-7.

28 Fagan EA, Dyck RF, Maton PN, Hodgson HJ, Chadwick VS, Petrie A, et al. Serum levels of C-reactive protein in Crohn's disease and ulcerative colitis. Eur $\mathcal{F}$ Clin Invest 1982; 12: disease

29 Cooke WT, Fowler DI, Cox EV, Gaddie R, Meynell MJ. The clinical significance of seromucoids in regional ileitis and clinical significance of seromucoids in regional

30 Kaufman S, Chalmer B, Heilman R, Beeken WA. A prospective study of the course of Crohn's disease. Dig Dis Sci 1979; 24: $269-76$.

31 Andre C, Descos L, Vignal J. C-Reactive protein level predicts Crohn's disease relapse in quiescent patients. Gut 1979; 20 A940.

32 Boirivant $M$, Leoni $M$, Tariciotti D, Fais S, Squarcia $O$, Pallone $F$. The clinical significance of serum C-reactive protein levels in Crohn's disease. Results of a prospective longitudinal study. F Clin Gastroenterol 1988; 10: 401-5.

33 Giaffer $\mathrm{MH}$, Tindale WB, Barber D, Holdsworth CD. Definition of remission in Crohn's disease using a computer controlled estimation of bowel uptake of Tc-99m Hexamethyl Propylene Amine Oxime (HMPAO) leucocyte bowel scanning. Gut 1990; 31: A1187. 